\title{
Smoking and Tobacco Use: Ill Effects on Reproductive, Maternal, Newborn, Child Health, and Adolescent (RMNCHA) Program-A Review
}

\author{
Suneeta Mittal ${ }^{1}$ \\ ${ }^{1}$ Department of Obstetrics and Gynecology, Fortis Memorial \\ Research Institute, Gurugram, Haryana, India
}

\begin{abstract}
Address for correspondence Suneeta Mittal, MD, FRCOG, FICOG, FAMS, FICMCH, FIMSA, FICLS, 890, Sector 15, Part 2, Gurugram 122002, Haryana, India (e-mail: suneeta.mittal@gmail.com).
\end{abstract}

\begin{abstract}
Keywords

- smoking

- reproductive health

- fertility

- maternal health

- perinatal outcome

- miscarriage

- smokeless tobacco use

- pregnancy

- passive smoking

Most people are aware that tobacco causes cancer, heart disease, chronic obstructive pulmonary disease, and major health problems, leading to high morbidity and mortality; however, many are not aware of its ill effects on the reproductive health of men and women as well as their children. This article has summarized the current research evidence from literature search to date, including prevalence of tobacco use, types of tobacco use, its effects on male and female fertility, pregnancy and their progeny in utero, neonatal period, childhood, adolescence, and subsequent well-being, with both active and passive smoking and smokeless tobacco use. Although antitobacco campaigns show horrifying visuals linked to tobacco use, not much progress has been made in controlling its use. Publicizing these harmful effects on pregnancy and progeny, making public aware, screening women coming for infertility or antenatal care on any form of tobacco use, and helping them to quit tobacco use may help the National Tobacco Control program, as parents are more concerned if they learn that there is harm to their fertility and progeny. Indirectly, it will help to improve reproductive, maternal, neonatal, child, and adolescent health.
\end{abstract}

\section{Introduction}

Globally, rates of smoking and tobacco use among women are increasing, whereas smoking rates in men show a slow decline. The use of tobacco in middle- and low-income countries is rising and is usually linked to low-income and low-educational status. ${ }^{1}$ India is increasingly facing a double burden of disease, and the burden attributed to noncommunicable diseases (NCDs) is growing. Tobacco use is identified as a major NCD behavioral risk factor contributing to several chronic diseases, including cancer, lung diseases, and cardiovascular diseases. India, along with other countries, has endorsed the target of a $25 \%$ reduction in premature mortality from NCDs by 2025 , and $30 \%$ reduction in tobacco use will significantly contribute to achieve this goal.

The use of tobacco in any form, including exposure to second-hand smoke (SHS), adversely affects the functioning of most organ systems of our body. Tobacco use has harmful effects on women through all stages of their lives, starting from childhood through adolescence and reproductive life, extending even into the postmenopausal decades. Most people are aware of the ill effects of tobacco such as respiratory, coronary, and vascular disease, chronic obstructive lung disease, and several types of cancers. However, the adverse effects on reproductive health including increased risk of fetal loss and higher incidence of preterm and low birth babies are rarely publicized. This article reviews the ill effects of smoking and tobacco use in the context of the Government of India Reproductive, Maternal, Newborn, Child Health, and Adolescent (RMNCHA) program.

\section{Materials and Methods}

A literature search was performed in PubMed and Medline using key terms such as "tobacco use," "smoking and reproductive health," "tobacco and pregnancy," "tobacco and 
neonatal outcome," "exposure to passive smoking during pregnancy," "tobacco and child and adolescent health." All research articles, observational and epidemiological studies, systematic reviews, and meta-analyses focusing on the ill effects of tobacco use in any form on reproductive health have been reviewed, and the observations have been categorized into specific areas to enable the reader to have a comprehensive overview of this issue. As research in this field is limited and a vast range of reproductive health issues have been covered, it is not possible to carry out a systematic review. All relevant literature published on this issue has been analyzed.

\section{Results}

There are several epidemiological studies published on the ill effects of tobacco use on reproductive health from several countries including India. Besides, some systematic reviews and prospective cohort studies have also evaluated the effect on pregnancy and its outcome. Few research papers have analyzed the adverse effects of tobacco at a molecular level. After reviewing epidemiology of tobacco use and forms of tobacco use globally and in India, the results have been categorized under specific subheadings, focusing on the ill effects on the reproductive health of women with fertility issues, influence on pregnancy and its outcome, problems in neonates, infants, children, and adolescents, and well-being during adult life due to direct and indirect tobacco exposure in utero.

\section{Epidemiology of Tobacco Use in Women}

Despite the evidence of the negative effects of tobacco use, the centers for Disease Control and Prevention (CDC) in the United States reports that $18 \%$ of women older than 18 years smoked cigarettes in $2009 .^{2}$ This rate of smoking has remained largely unchanged over the past 5 years, thus falling short of the Healthy People 2010 goal of a smoking rate of $12 \%$ or less. ${ }^{2}$ More than $80 \%$ of "current" smokers start before age 18 , and lower levels of education and economically backwardness increase the prevalence of tobacco use in women.

There is a paucity of epidemiological data on women in developing countries. Nonetheless, numerous surveys worldwide and in India show a greater prevalence of tobacco use among the less educated and illiterate. In a large population-based study in Mumbai, ${ }^{3}$ the odds ratios (ORs) for any kind of tobacco use among the illiterate as compared with the college-educated were 7.4 for males and 20.3 for females after adjusting for age and occupation. Overall, school dropouts are more likely to take to tobacco use in childhood and adolescence.

As per the Global Adult Tobacco Survey (GATS), India, 2010, India has alarmingly high rates of tobacco consumption. ${ }^{4}$ Almost 275 million Indian adults, nearly 35\% of the population, consume some form of tobacco. The key findings of GATS highlight that $20.3 \%$ of adult women use tobacco products and more than $90 \%$ women tobacco users consume smokeless tobacco (a large number of these users are in the reproductive age group). The average age at initiation of tobacco use was 17.8 years, with $25.8 \%$ of females starting tobacco use before the age of 15 years. Besides the use of smokeless tobacco, exposure to passive smoking is very common in India. Currently, the tobacco industry is trying to target and attract women aggressively into tobacco use by projecting smoking as something modern and fashionable. Even antitobacco lobbies give a lot of emphasis on curbing tobacco use for preventing lung and oral cancer, and very little attention is being paid to its ill effects on reproductive health women and their progenies.

\section{Different Forms of Tobacco Use}

The most common form of tobacco addiction is smoking. Cigarettes are very popular and a glamorized form of tobacco use in most countries including India. Hand-rolled "bidis" are also popular among women of our country, especially those who are illiterate with low socioeconomic status. In recent years, tobacco products have changed, and several others have been developed or are gaining popularity. There are many flavors of cigarettes, cigars, and other forms of tobacco that are available for sale. Menthol cigarettes increase the likelihood and degree of nicotine addiction in new smokers and make smoking cessation more difficult. ${ }^{5}$ The more recent forms of smoking alternatives include a gel strip impregnated with nicotine that melts on the tongue and an electronic or e-cigarette, a battery-powered device that heats cartridges of liquid containing nicotine to create a mist, which users inhale.

Smokeless tobacco products are mistakenly believed to be a safer and may be a more convenient alternative to cigarettes where smoking is prohibited. In India, various types of chewing tobacco products and common forms of smokeless tobacco use are paan with tobacco, bajjar, gudhaku, mishri, and laldantmanjan and creamy snuff used as dentifrice for cleaning teeth. One form of smokeless tobacco popular with young women is "snus," a flavored self-contained tobacco pouch that is placed between the cheek and gum and does not require spitting.

Use of oral snuff and smoking tobacco with a water pipe (hookahs and chilim) are some other forms of tobacco use seen among the rural Indians. Hookahs, or tobacco water pipes, are popular among youth or young adults. When using a hookah, inhalation is usually deeper and smoking sessions are longer than with a typical cigarette. This leads to higher concentration of toxins after hookah smoking compared with cigarette smoking. ${ }^{6}$

Many Indian women are also involved in tobacco farming or "bidi" rolling. Additionally, there may be others who are employed in cigarette manufacturing companies. These are examples of occupational exposure to tobacco. Most modern cities have too many vehicles on road emitting smoke. The air pollution is yet another manner in which women can be exposed to health hazards.

"Passive smoking" or exposure to SHS is another way a woman may be at risk even when she herself does not smoke, as husband or other relatives smoke in her vicinity, with some of them heavily. 


\section{Effects of Tobacco Use on Reproductive Health}

Tobacco smoking has a negative influence on female (as well male) fertility and is even known to cause health issues for postmenopausal women, such as osteoporosis.

\section{Smoking and Fertility}

It is clearly established that smoking can have a negative impact on female fertility. Women who smoke take longer to conceive than women who do not smoke. ${ }^{7}$ The greater the quantity of cigarette smoked, the longer a woman is likely to take to achieve pregnancy. ${ }^{8}$ It is suggested that tobacco consumption affects uterine receptivity; this effect is more likely with heavy smokers. ${ }^{9}$ Interestingly, even comparatively low levels of smoking do seem to have a significant impact on female fertility. There is also a higher rate of ectopic pregnancies in smokers. ${ }^{10}$

There is evidence to suggest that smoking reduces the success rates of fertility treatment. ${ }^{11}$ Women undergoing assisted reproductive technology (ART) treatment demonstrate a significant negative effect associated with smoking. ${ }^{12,13}$ In a study evaluating 200 in vitro fertilization (IVF)/intracytoplasmic sperm injection cycles, the endometrial thickness in smoking patients was significantly less than nonsmoking patients. ${ }^{14}$

There have been reports of substantial reduction (nearly $50 \%$ in implantation rates among smokers compared with nonsmokers. ${ }^{15}$ A study involving IVF cycles with oocyte donors showed that ovarian response was significantly reduced in donors who smoked. However, the oocyte quality, pregnancy rate, and live birth rates were not affected by smoking. ${ }^{16}$ A dysregulation of reproductive and hormonal systems caused by maternal smoking reduces the probability of pregnancy in both healthy women and those undergoing ART treatment. ${ }^{17}$

Smoking in men results in erectile dysfunction, lower sperm quality, and decreased testosterone levels, thus lowering the chances of pregnancy. Some of the early reports suggest that smoking during pregnancy has an impact on protamine, a protein essential in sperm production that can lead to fertility problems. ${ }^{18}$ Men who smoke have lower sperm count, higher proportion of malformed sperms, and reduced sperm motility. ${ }^{19} \mathrm{~A}$ meta-analysis of studies published since 1980 found that 40 to $80 \%$ of current smokers were impotent compared with $28 \%$ men in general population. ${ }^{20}$

Furthermore, a growing body of research suggests that maternal smoking may have a negative impact on the fertility of both female and male offspring. ${ }^{21,22}$ Smoking during pregnancy reduces the number of germ cells and somatic cells that form in the developing fetus. ${ }^{23}$

\section{Effects on Maternal Health}

\section{Smoking during Pregnancy}

In the United Kingdom, by March 2012, the proportion of women smoking at the time of delivery was $13 \%$. This equates to approximately 83,000 infants born to smoking mothers each year. ${ }^{24}$ The 2010 Infant Feeding Survey also reports that nearly $26 \%$ of mothers smoked in the 12 months before or during their pregnancy. These figures are down from $33 \%$ in
2005. ${ }^{25}$ Nearly one (54\%) of two women who smoked before pregnancy managed to stop once they became pregnant. But sadly, $12 \%$ (one out of eight) mothers-to-be continued to smoke throughout their pregnancy. U.S. data from 27 states by the Pregnancy Risk Assessment and Monitoring System ${ }^{26}$ shows that $\sim 10.7 \%$ of women reported smoking during the last 3 months of pregnancy; however, of women who smoked 3 months before pregnancy, 54\% (one out of two) quit during pregnancy, though $44 \%$ relapsed to smoking again within 6 months after delivery.

In contrast, a significant fall was noticed in England, with only $14 \%$ of mothers reporting to be smoking at delivery in England in 2010. Smoking rates, though, vary significantly throughout the United Kingdom. ${ }^{27}$ Those who were young (under the age of 20 years) at the time of conception were significantly more likely to smoke before or during pregnancy compared with older mothers (over the age of 35 years). ${ }^{28}$

Studies have shown that during pregnancy, women consciously reduce the use of tobacco products, alcohol, and caffeine, ${ }^{29}$ though it may not make significant changes in their lifestyle or dietary pattern. ${ }^{30}$

In an editorial published in the Indian Journal of Medical Research, ${ }^{31}$ it has been reported that Indian women generally do not smoke, though the situation may differ from state to state. ${ }^{32}$ In India, reproductive health services do not address tobacco problem at all. But, the prevalence of smokeless tobacco use among women in India is quite high and recent data show that smokeless tobacco use during pregnancy ${ }^{33,34}$ causes nearly the same adverse impact as tobacco smoking. A recent survey has shown that $23 \%$ women were exposed to SHS and $6.1 \%$ smoked during pregnancy. ${ }^{35}$

\section{Adverse Impact on Pregnancy}

According to a CDC report, the health hazards of smoking during pregnancy ${ }^{26}$ include more likelihood of having a miscarriage or an abortion, problems with the placenta including placental abruption or placenta previa, prematurity and growth restriction in baby, stillbirth or longer stay in the hospital, risk of sudden infant death syndrome (SIDS or cot death), and certain birth defects such as a cleft lip or cleft palate. There is a recent report evaluating the effect of smoke extract on placental macrophage function, ${ }^{36}$ which may be responsible for the adverse pregnancy outcome.

\section{Miscarriage}

Miscarriage is usually due to genetic defects induced by nicotine. Smoking may also alter the endometrium, making it more difficult for implantation to take place. There is some evidence that a father who smokes in excess of 20 cigarettes per day may increase the chances of miscarriage because his sperm may get damaged. Some studies indicate that men who smoke have a higher incidence of chromosomal abnormalities in their sperm. ${ }^{19}$ Besides, exposure to SHS increases the abortion risk in mother.

A meta-analysis and a 2014 systematic review has reported an increased risk of miscarriage in active smokers, with risk increasing proportionately to the number of cigarettes smoked. ${ }^{37}$ Early pregnancy loss is higher in women who 
smoke and conceive following ART treatment. ${ }^{38} \mathrm{~A}$ study from the University of Newcastle, New South Wales, Australia, ${ }^{39}$ reported that current smokers and ex-smokers had an increased risk of miscarriages compared with women who had never smoked, with the highest risk occurring in heavy smokers (adjusted ORs for those smoking 20 or more cigarettes per day: 2.0 ).

\section{Fetal Growth Restriction and Low Birth Weight}

Maternal smoking is a major risk factor for low birth weight and small for -gestational age babies. ${ }^{40-43}$ Swedish researchers have shown that babies born to women who smoke throughout their pregnancy are on average 162 to $226 \mathrm{~g}$ lighter than babies born to nonsmoking mothers. ${ }^{44}$ This was also documented in research performed in Spain. ${ }^{45}$ Another study reported that maternal smoking could be an independent risk factor in nearly $30 \%$ of growth-restricted neonates. ${ }^{46}$ Researchers have documented that smoking during pregnancy leads to smaller head circumference and slower growth of the fetal head. ${ }^{47-49}$

\section{Preterm Births}

Recent research in Sweden examined the relationship between maternal smoking and preterm birth. It was found that compared with nonsmokers, moderate smokers had a twofold increase in risk of preterm labor; this risk increases to two and a half times among heavy smokers. ${ }^{50}$ An experimental study of amnion exposed to cigarette smoke condensate has shown alteration in the retinoid pathway in amnion-derived epithelial cells. These play a significant role in pathophysiology of membrane rupture and preterm birth. ${ }^{51}$ Mouse exposed to e-cigarette have shown altered DNA methylation and lung cytokine expression in their offspring, similar to mechanisms described for preterm birth. ${ }^{52}$

\section{Congenital Malformations}

There is an increased risk of congenital defects in the offspring of smokers. ${ }^{53}$ The most commonly reported birth defects include orofacial clefts (cleft lip or cleft palate), ${ }^{54-56}$ neural tube defects (defects of the defects of the brain, spine, or spinal cord), ${ }^{57,58}$ cardiovascular/heart defects, musculoskeletal defects, limb reduction defects, missing/extra digits, clubfoot, craniosynostosis (fused skull bones that may affect brain growth), facial defects, eye defects, gastrointestinal defects, gastroschisis, anal atresia, hernia, and undescended testes. ${ }^{59}$

A meta-analysis of 23 articles showed a higher risk of neural tube defects in neonateswhen mothers smoked (OR: 1.05), and this further increased with exposure to passive smoking. ${ }^{60}$ Evaluation of cryptorchidism in Down's syndrome has shown that $55 \%$ of these were children of mothers who smoked during pregnancy. Prevalence of cryptorchidism increased 3.89 times in children exposed to paternal smoke. ${ }^{61}$

\section{Adverse Effects on Neonatal Health}

Tobacco use during pregnancy not only harms in utero development of fetus but also continues to have adverse effects on neonate, infant, child and adolescents. Some of these in utero exposed babies continue to manifest some problems even during adult life.

Perinatal Mortality and Sudden Infant Death Syndrome It is estimated that about one-third of all perinatal deaths including stillbirths and early neonatal deaths in the United Kingdom are caused by maternal smoking. ${ }^{62,63}$ Evidence has demonstrated that babies born to women who smoke during pregnancy are around $40 \%$ more likely to die within the first 4 weeks of life than babies born to nonsmokers. ${ }^{43,64}$ A meta-analysis of risk factors in 886,505 women from nine states of India showed that tobacco chewing women (\% of total) had higher odds of having stillbirth (OR: 1.1; 95\% confidence interval [CI]: 1.02-1.21) after excluding other confounding factors. ${ }^{65}$ Lessons learned from epidemiological and experimental animal model studies confirm these observations. ${ }^{66}$

More than one-quarter of the risk of death due to SIDS is attributable to smoking during pregnancy and exposure to SHS, particularly in the home. ${ }^{67,68}$ McDonnell-Naughton et al report that the risk of cot death has trebled in infants whose mothers smoke both during and after pregnancy. ${ }^{69}$ Postnatal parental smoking is cited as an important risk factor for SIDS. Indeed, the greater the number of cigarettes smoked, the higher the risk of SIDS. ${ }^{70}$ It is likely that nicotine from tobacco smoke (including its derivatives) easily reach the cerebrospinal fluid in the fetus to cause ependymal damage (the lining providing a protective barrier and filtration system separating the brain from cerebrospinal fluid). The best way to reduce the risk of SIDS or cot death is to maintain a smoke-free home and vehicle at all times. ${ }^{71}$

\section{Smoking and Breastfeeding}

Longer periods of abstinence from smoking are linked to better initiation of breastfeeding. Women who have quit smoking for at least a month are more likely to initiate breastfeeding. ${ }^{72}$ Additionally, women who quit smoking tend to continue breastfeeding for a longer period of time than those who continue to smoke. ${ }^{73}$ Indeed, breastfeeding is still recommended by the National Health Service and the American Academy of Pediatrics, among others, because of its beneficial effects on the baby, even if the mother continues to smoke. It is important therefore that the health care professionals combine smoking cessation and relapse-prevention advice with lactation counseling in women who smoke to maximize success of smokers' efforts to initiate breastfeeding.

\section{Adverse Effects on Child Health}

Effects on Childhood Growth Development and Behavior One study found that maternal smoking during pregnancy is linked to high fetal testosterone. This leads to an increased risk of autism, childhood attention deficit/hyperactivity disorder (ADHD), conduct disorder, and antisocial behavior. ${ }^{74}$ Numerous other studies have demonstrated a link between maternal smoking and ADHD. ${ }^{75,76}$ Data from a recent study also incriminate SHS in causing ADHD. ${ }^{77}$

A population-level study of Finnish children documented that the risk of psychiatric morbidity was significantly 
higher among children of mothers who smoked during pregnancy. ${ }^{78}$ Studies have found that smoking during pregnancy and exposure to SHS in early childhood were "quite strong" predictors of conduct problems, antisocial behavior, and crime later in life. ${ }^{79}$ This finding is supported by other studies exploring the relationship between maternal smoking during pregnancy and behavior problems in childhood and adolescence, $^{80,81}$ including smoking (particularly among girls) ${ }^{82}$ and other substance use. ${ }^{83}$

Maternal smoking has been associated with an increased risk of learning difficulties ${ }^{84}$ Prenatal exposure to environmental tobacco smoke in Chinese children has been associated with hyperactive behavior (OR: 1.51) compared with those born to nonexposed mothers. A meta-analysis of offspring with prenatal exposure to maternal smoking has shown a significant association with childhood ADHD. ${ }^{85}$ Preand postnatal exposure to tobacco results in higher sleep problems in girls at 3 years of age. ${ }^{86}$

In an evaluation of scholastic achievements of offspring of mothers who smoked during pregnancy, childhood in 4th, 7 th and 10th grade revealed 5 to $7 \%$ lower score compared with children of nonsmoking mothers after controlling for other factors affecting childhood performance. ${ }^{87}$

\section{Effects on Child Health}

There is some evidence to suggest that pre- and postnatal SHS contributes to insulin resistance in children. ${ }^{88}$ There is strong evidence that childhood obesity can be related to smoking during pregnancy. ${ }^{89}$ Two meta-analyses of 7 and 14 studies, respectively, found that for children of mothers who smoked during pregnancy, there was a 47 to $50 \%$ increase in the odds of being overweight in childhood. ${ }^{90,91}$

A meta-analysis of 11 articles analyzing 4,833 children with strabismus concluded that antenatal smoking during pregnancy is significantly associated with strabismus in offspring (OR: 1.46; 95\% CI: 1.32-1.60) when mother smoked less than 10 cigarettes per day and increased further (OR: 1.79; $95 \%$ CI: $1.39-2.31$ ) if she smoked more than 10 cigarettes per day. ${ }^{92}$

A meta-analysis evaluating 14 case-control studies involving 3,114 children with neuroblastoma showed an association with tobacco use during pregnancy (OR: 1.22). ${ }^{93}$

\section{Adverse Effects on Adolescent Health Adolescent Health Risks}

Prenatal multidrug exposure including tobacco has been correlated with adolescent cognition and attention disorders and with higher rates of substance abuse. ${ }^{94}$ An analysis of seven databases evaluating prenatal tobacco exposure and puberty timing observed that it decreases the age of menarche in girls. ${ }^{95}$ Gestational tobacco exposure has also been associated with adolescent tobacco dependence and higher use of e-cigarettes. ${ }^{96}$

\section{Late Manifestations in Adult Life}

Both maternal smoking and paternal smoking have been associated with low sperm counts in the sons. Sons of smoking fathers have $51 \%$ lower sperm count. ${ }^{97}$
It is reported that exposure to cigarette smoke in early fetal developmental can result in certain epigenetic changes in the lungs of the offspring. These can then be transferred to following generations, resulting in adult onset of respiratory disease. $^{98}$ There is some evidence of an association between maternal smoking, early childhood exposure to SHS, and the development of emphysema in adulthood. The preceding findings suggest that the lungs may not recover completely from the effects of early life exposure, even when the offspring continues to be nonsmoker in adult life.99,100

Perinatal exposure to environmental tobacco smoke has been associated with altered DNA methylation in mice. This epigenetic finding could represent a potential biomarker for adult respiratory disease. ${ }^{101}$ Another experiment exposing mice to e-cigarettes has shown altered DNA methylation and lung cytokine expression in their offspring. ${ }^{52}$ This may be responsible for pulmonary dysfunction at a later age.

Several researchers have also found that adults exposed to tobacco smoke in utero had a more adverse cardiovascular disease risk profile. ${ }^{102}$ Some evidence suggests that prenatal exposure to tobacco smoke may be associated with benign breast disease later in life. ${ }^{103}$

\section{Passive Smoking and Pregnancy}

Passive smoking is perhaps more relevant to Indian setting as the number of women smoking while pregnant is far less, with high exposure to SHS. However, SHS is associated with similar maternal and fetal risks as is active smoking. SHS exposure during pregnancy has been correlated with lower quality of life and higher incidence of postpartum depression in women, besides its ill effects already discussed. ${ }^{104}$ According to a report from U.S. Surgeon General, second-hand tobacco smoke is a mixture of at least 4,000 chemical compounds, ${ }^{105}$ many of which are likely to be reproductive toxins. ${ }^{15}$ Nonsmoking women exposed to other people's tobacco smoke during pregnancy are more likely to have lower weight babies. ${ }^{106,107}$

Several other researchers have reported that nonsmoking women who are exposed to SHS are at an increased risk of infertility or have difficulty becoming pregnant, ${ }^{108}$ giving birth prematurely of stillbirth, ${ }^{109,110}$ spontaneous abortion, ${ }^{111}$ and having a baby with congenital malformations. Additionally, some evidence suggests that female fertility can be damaged in utero if the woman's mother was exposed to SHS while pregnancy. ${ }^{21}$ Exposure to SHS can also be damaging in terms of successful pregnancy outcomes for women undergoing IVF or other ART treatment. ${ }^{10,112,113}$ ADHD has also been linked to SHS exposure in the home, in addition to maternal smoking during pregnancy. ${ }^{114}$ Exposure to parental SHS in the home and vehicle is strongly associated with middle ear disease in children. ${ }^{115}$ There is some evidence to suggest that prenatal and postnatal SHS may cause leukemia, ${ }^{116}$ especially acute lymphoblastic leukemia.

It must be appreciated that research on the reproductive effects of SHS exposure is relatively new compared with that on the effects of active smoking. More epidemiologic research is likely to reveal additional negative health effects, as well as the mechanisms whereby they occur and the dose-response relationships involved. 


\section{Smoking and Oral Contraception}

It is generally known that women using combined oral contraceptives are at an increased risk of heart disease. However, since the risk of heart disease in young women is low, the benefits of using the pill generally outweigh the risks for young women who do not smoke. This is not the same with women who smoke. In addition, pill users who smoke are also at a risk of venous thromboembolism and arterial thrombosis. ${ }^{17-119}$ It is, therefore, important that all women who take the contraceptive pill be counseled against smoking and advised on the use of alternative method of contraception.

\section{Smoking and Menopause}

Women who smoke seem to attain menopause at an early age, ${ }^{120}$ with the natural menopause occurring up to 2 years earlier in smokers. The likelihood of earlier menopause is related to the number of cigarettes smoked; those smoking more than 10 cigarettes a day have an increased risk of early menopause. ${ }^{121}$ It must be emphasized that stopping smoking may lower the risk of early menopause. Research suggests that polycyclic aromatic hydrocarbons found in tobacco smoke can trigger premature egg cell death, which may, in turn, lead to earlier menopause. ${ }^{122}$ Another study suggests that chemicals in tobacco smoke alter endocrine function, which, in turn, affects the release of pituitary hormones. This endocrine disruption is thought to contribute to adverse outcomes, including earlier menopause. ${ }^{123}$

Postmenopausal women who smoke have lower bone density than women who never smoked. Women who smoke have an increased risk of hip fracture compared with never smokers. Cigarette smoking also causes skin wrinkling that could make smokers appearance less attractive and prematurely old.

\section{Conclusion}

Smoking (or tobacco) seems to adversely impact the health of women in all stages of their life, starting from birth to senescence. There is a growing body of evidence that smoking causes "preventable" harm to women's health, with the ill effects being most profound during pregnancy and immediate puerperium.

The adverse impact of smoking is linked to the number of years of smoking and number of cigarettes smoked each day, and when done during pregnancy, it has a far-reaching adverse impact on the health of her progeny. In India, passive smoking or SHS is also very important.

Knowing the profound ill effects of tobacco, it is worth spending large sums of money on helping people stay away from tobacco addiction. Smoking cessation is possible with the right support and help from health care professionals along with government agencies and self-help groups. Pregnancy and childbirth provide the best opportunity when women are most likely to be motivated to quit smoking (for the sake of the child). By dissuading people from the use of tobacco (in any form), we can prevent several illnesses and substantially reduce the overall disease burden. This translates into better health and improved quality of life for our citizens and would lead to huge savings in government expenditure. Thus, screening for smoking and tobacco use and measures to stop should be integral components of the RMNCHA program in India. Tobacco cessation training needs to be imparted to the care providers, and there is a need to discuss the synergistic role of tobacco control with the basic goal of reducing maternal and child mortality.

In light of the serious health consequences and the strong motivation of pregnant women to ensure the health of their newborns, efforts to help pregnant women quit smoking (and to prevent postpartum relapse) should be accorded a high priority in public health programs focusing on women and children. A mechanism needs to be developed to integrate tobacco control prevalence indicators and cessation advice in the health care delivery system for women.

\section{Conflict of Interest}

None declared.

\section{Acknowledgments}

A national consultation on tobacco use and its implications on the health of women and their children was organized by the author at Fortis Memorial Research Institute in collaboration with World Health Organization, Ministry of Health and Family Welfare (Government of India), and Indian Council of Medical Research on World No Tobacco Day in 2013. The author is grateful to all the resource persons who participated in the consultation.

\section{References}

1 Global Adult Tobacco Survey. Fact Sheet, India 2016-2017. Available at: https://www.who.int/tobacco/surveillance/survey/gats/GATS_India_2016-17_FactSheet.pdf. Accessed July 11, 2019

2 National Centre for Health Statistics. Centers for Disease Control and Prevention. Cigarette Smoking during Pregnancy: United States, 2009. Available at: https://www.cdc.gov/nchs/ products/databriefs/db305.htm. Accessed July 11, 2019

3 Gupta PC, Ray CS. Tobacco, education \& health. Indian J Med Res 2007;126(4):289-299

4 Sharma S, Singh M, Lal P, Goel S. Predictors of tobacco use among youth in India: GATS 2009-2010 survey. Asian Pac J Cancer Prev 2015;16(17):7535-7540

5 Benowitz NL, Samet JM. The threat of menthol cigarettes to U.S. public health. N Engl J Med 2011;364(23):2179-2181

6 Knishkowy B, Amitai Y. Water-pipe (narghile) smoking: an emerging health risk behavior. Pediatrics 2005;116(1):e113-e119

7 Practice Committee of the American Society for Reproductive Medicine. Smoking and infertility: a committee opinion. Fertil Steril 2012;98(6):1400-1406

8 Curtis KM, Savitz DA, Arbuckle TE. Effects of cigarette smoking, caffeine consumption, and alcohol intake on fecundability. Am J Epidemiol 1997;146(1):32-41

9 Soares SR, Simon C, Remohí J, Pellicer A. Cigarette smoking affects uterine receptiveness. Hum Reprod 2007;22(2):543-547

10 Anderson K, Nisenblat V, Norman R. Lifestyle factors in people seeking infertility treatment - A review. Aust N Z J Obstet Gynaecol 2010;50(1):8-20 
11 Dechanet C, Brunet C, Anahory T, Hamamah S, Hedon B, Dechaud $\mathrm{H}$. Effects of cigarette smoking on embryo implantation and placentation and analysis of factors interfering with cigarette smoke effects (Part II) [in French]. Gynécol Obstét Fertil 2011;39(10):567-574

12 Neal MS, Hughes EG, Holloway AC, Foster WG. Sidestream smoking is equally as damaging as mainstream smoking on IVF outcomes. Hum Reprod 2005;20(9):2531-2535

13 Waylen AL, Metwally M, Jones GL, Wilkinson AJ, Ledger WL. Effects of cigarette smoking upon clinical outcomes of assisted reproduction: a meta-analysis. Hum Reprod Update 2009;15(1):31-44

14 Heger A, Sator M, Walch K, Pietrowski D. Smoking decreases endometrial thickness in IVF/ICSI patients. Geburtshilfe Frauenheilkd 2018;78(1):78-82

15 Meeker JD, Benedict MD. Infertility, pregnancy loss and adverse birth outcomes in relation to maternal secondhand tobacco smoke exposure. Curr Womens Health Rev 2013;9(1):41-49

16 Fréour T, Massart P, García D, Vassena R, Rodríguez A. Revisiting the association between smoking and female fertility using the oocyte donation model. Reprod Biomed Online 2018;37(5):564-572

17 Jandíková $\mathrm{H}$, Dušková $\mathrm{M}$, Stárka L. The influence of smoking and cessation on the human reproductive hormonal balance. Physiol Res 2017;66(Supplementum 3):S323-S331

18 Hammadeh ME, Hamad MF, Montenarh M, FischerHammadeh C. Protamine contents and P1/P2 ratio in human spermatozoa from smokers and non-smokers. Hum Reprod 2010;25(11):2708-2720

19 Sofikitis N, Takenaka M, Kanakas N, et al. Effects of cotinine on sperm motility, membrane function, and fertilizing capacity in vitro. Urol Res 2000;28(6):370-375

20 Tengs TO, Osgood ND. The link between smoking and impotence: two decades of evidence. Prev Med 2001;32(6):447-452

21 Ye X, Skjaerven R, Basso O, et al. In utero exposure to tobacco smoke and subsequent reduced fertility in females. Hum Reprod 2010;25(11):2901-2906

22 Ramlau-Hansen CH, Thulstrup AM, Storgaard L, Toft G, Olsen $\mathrm{J}$, Bonde JP. Is prenatal exposure to tobacco smoking a cause of poor semen quality? A follow-up study. Am J Epidemiol 2007;165(12):1372-1379

23 Mamsen LS, Lutterodt MC, Andersen EW, et al. Cigarette smoking during early pregnancy reduces the number of embryonic germ and somatic cells. Hum Reprod 2010;25(11):2755-2761

24 Health and Social Care Information Centre, Statistical Release. Statistics on Women's Smoking Status at Time of Delivery: England - Quarter 4 2012/13

25 Health and Social Care Information Centre, Chapter 11. Dietary Supplements, Smoking and Drinking during Pregnancy. In: Infant Feeding Survey - UK, 2010 (NS). 2012 Nov 20

26 Centers for Disease Control and Prevention. Substance Use During Pregnancy. Available at: http://www.cdc.gov/ reproductivehealth/tobaccousepregnancy/index.htm. Accessed January 16, 2019

27 Health and Social Care Information Centre, Wide Regional Variation in Percentage of Women Who Smoke at the Time of Delivery. February 16, 2012

28 Flemming K, Graham H, Heirs M, Fox D, Sowden A. Smoking in pregnancy: a systematic review of qualitative research of women who commence pregnancy as smokers. J Adv Nurs 2013;69(5):1023-1036

29 Crozier SR, Robinson SM, Borland SE, Godfrey KM, Cooper C, Inskip HM; SWS Study Group. Do women change their health behaviours in pregnancy? Findings from the Southampton Women's Survey. Paediatr Perinat Epidemiol 2009;23(5):446-453

30 Inskip HM, Crozier SR, Godfrey KM, Borland SE, Cooper C, Robinson SM; Southampton Women's Survey Study Group.
Women's compliance with nutrition and lifestyle recommendations before pregnancy: general population cohort study. BMJ 2009;338:b481

31 Gupta PC. Tobacco control in India. Indian J Med Res 2006;123(5):579-582

32 Sinha DN, Gupta PC, Pednekar MS, Jones JT, Warren CW. Tobacco use among school personnel in Bihar, India. Tob Control 2002;11(1):82-83

33 Gupta PC, Subramoney S. Smokeless tobacco use, birth weight, and gestational age: population based, prospective cohort study of 1217 women in Mumbai, India. BMJ 2004;328(7455):1538-1540

34 Gupta PC, Subramoney S. Smokeless tobacco use and risk of stillbirth: a cohort study in Mumbai, India. Epidemiology 2006;17(1):47-51

35 Do EK, Green TL, Prom-Wormley EC, Fuemmeler BF. Social determinants of smoke exposure during pregnancy: findings from waves $1 \& 2$ of the Population Assessment of Tobacco and Health (PATH) Study. Prev Med Rep 2018;12:312-320

36 Belhareth R, Mezouar S, Ben Amara A, et al. Cigarette smoke extract interferes with placenta macrophage functions: a new mechanism to compromise placenta functions? Reprod Toxicol 2018;78:120-129

37 Pineles BL, Park E, Samet JM. Systematic review and meta-analysis of miscarriage and maternal exposure to tobacco smoke during pregnancy. Am J Epidemiol 2014;179(7):807-823

38 Winter E, Wang J, Davies MJ, Norman R. Early pregnancy loss following assisted reproductive technology treatment. Hum Reprod 2002;17(12):3220-3223

39 Mishra GD, Dobson AJ, Schofield MJ. Cigarette smoking, menstrual symptoms and miscarriage among young women. Aust N Z J Public Health 2000;24(4):413-420

40 Vielwerth SE, Jensen RB, Larsen T, Greisen G. The impact of maternal smoking on fetal and infant growth. Early Hum Dev 2007;83(8):491-495

41 Agrawal A, Scherrer JF, Grant JD, et al. The effects of maternal smoking during pregnancy on offspring outcomes. Prev Med 2010;50(1-2):13-18

42 McCowan L, Horgan RP. Risk factors for small for gestational age infants. Best Pract Res Clin Obstet Gynaecol 2009;23(6):779-793

43 Department of Health, Local Stop Smoking Services: Service delivery and monitoring guidance 2014. Available at: https:// www.ncsct.co.uk/publication_service_and_delivery_guidance_2014.php. Accessed July 11, 2019

44 Juárez SP, Merlo J. Revisiting the effect of maternal smoking during pregnancy on offspring birthweight: a quasi-experimental sibling analysis in Sweden. PLoS One 2013;8(4):e61734

45 Samper MP, Jiménez-Muro A, Nerín I, Marqueta A, Ventura P, Rodríguez G. Maternal active smoking and newborn body composition. Early Hum Dev 2012;88(3):141-145

46 Varvarigou AA, Fouzas S, Beratis NG. Effect of prenatal tobacco smoke exposure on fetal growth potential. J Perinat Med 2010;38(6):683-687

47 Roza SJ, Verburg BO, Jaddoe VW, et al. Effects of maternal smoking in pregnancy on prenatal brain development. The Generation R Study. Eur. J Neurosci 2007;25(3):611-617

48 Himes SK, Stroud LR, Scheidweiler KB, Niaura RS, Huestis MA. Prenatal tobacco exposure, biomarkers for tobacco in meconium, and neonatal growth outcomes. J Pediatr 2013;162(5):970-975

49 Andersen MR, Simonsen U, Uldbjerg N, Aalkjaer C, Stender S. Smoking cessation early in pregnancy and birth weight, length, head circumference, and endothelial nitric oxide synthase activity in umbilical and chorionic vessels: an observational study of healthy singleton pregnancies. Circulation 2009;119(6):857-864 
50 Kyrklund-Blomberg NB, Granath F, Cnattingius S. Maternal smoking and causes of very preterm birth. Acta Obstet Gynecol Scand 2005;84(6):572-577

51 Rouzaire M, Comptour A, Belville C, et al. Cigarette smoke condensate affects the retinoid pathway in human amnion. Placenta 2017;58:98-104

52 Chen H, Li G, Chan YL, et al. Maternal e-cigarette exposure in mice alters DNA methylation and lung cytokine expression in offspring. Am J Respir Cell Mol Biol 2018;58(3):366-377

53 Ellingson $\mathrm{JM}$, Rickert $\mathrm{ME}$, Lichtenstein $\mathrm{P}$, Långström $\mathrm{N}$, D'Onofrio BM. Disentangling the relationships between maternal smoking during pregnancy and co-occurring risk factors. Psychol Med 2012;42(7):1547-1557

54 Lebby KD, Tan F, Brown CP. Maternal factors and disparities associated with oral clefts. Ethn Dis 2010;20:S1 - 146-149

55 Shi M, Wehby GL, Murray JC. Review on genetic variants and maternal smoking in the etiology of oral clefts and other birth defects. Birth Defects Res C Embryo Today 2008;84(1):16-29

56 Crossan E, Duane B. Is there an association between maternal smoking and oral clefts? Evid Based Dent 2018;19(1):24-25

57 Suarez L, Felkner M, Brender JD, Canfield M, Hendricks K. Maternal exposures to cigarette smoke, alcohol, and street drugs and neural tube defect occurrence in offspring. Matern Child Health J 2008;12(3):394-401

58 Suarez L, Ramadhani T, Felkner M, et al. Maternal smoking, passive tobacco smoke, and neural tube defects. Birth Defects Res A Clin Mol Teratol 2011;91(1):29-33

59 Hackshaw A, Rodeck C, Boniface S. Maternal smoking in pregnancy and birth defects: a systematic review based on 173 687 malformed cases and 11.7 million controls. Hum Reprod Update 2011;17(5, Suppl):589-604

60 Meng X, Sun Y, Duan W, Jia C. Meta-analysis of the association of maternal smoking and passive smoking during pregnancy with neural tube defects. Int J Gynaecol Obstet 2018;140(1):18-25

61 Duarte AMBR, Bessa J, Jr. Mrad FCC, et al. Smoking and its association with cryptorchidism in Down syndrome. Rev Assoc Med Bras (1992) 2017;63(8):693-696

62 British Medical Association, Board of Science, Education and Tobacco Control Resource Centre

63 Smoking and reproductive life. The impact of smoking on sexual, reproductive and child health, London, BMA 2004

64 Figueras F, Meler E, Eixarch E, et al. Association of smoking during pregnancy and fetal growth restriction: subgroups of higher susceptibility. Eur J Obstet Gynecol Reprod Biol 2008;138(2):171-175

65 Altijani N, Carson C, Choudhury SS, et al. Stillbirth among women in nine states in India: rate and risk factors in study of 886,505 women from the annual health survey. BMJ Open 2018;8(11):e022583

66 Abbott LC, Winzer-Serhan UH. Smoking during pregnancy: lessons learned from epidemiological studies and experimental studies using animal models. Crit Rev Toxicol 2012;42(4):279-303

67 Rubens D, Sarnat HB. Sudden infant death syndrome: an update and new perspectives of etiology. Handb Clin Neurol 2013;112:867-874

68 Van Nguyen JM, Abenhaim HA. Sudden infant death syndrome: review for the obstetric care provider. Am J Perinatol 2013;30(9):703-714

69 McDonnell-Naughton M, McGarvey C, O'Regan M, Matthews T. Maternal smoking and alcohol consumption during pregnancy as risk factors for sudden infant death. Ir Med J 2012;105(4):105-108

70 Liebrechts-Akkerman G, Lao O, Liu F, et al. Postnatal parental smoking: an important risk factor for SIDS. Eur J Pediatr 2011;170(10):1281-1291
71 Behm I, Kabir Z, Connolly GN, Alpert HR. Increasing prevalence of smoke-free homes and decreasing rates of sudden infant death syndrome in the United States: an ecological association study. Tob Control 2012;21(1):6-11

72 Collins BN, DiSantis KI, Nair US. Longer previous smoking abstinence relates to successful breastfeeding initiation among underserved smokers. Breastfeed Med 2011;6(6):385-391

73 Higgins TM, Higgins ST, Heil SH, et al. Effects of cigarette smoking cessation on breastfeeding duration. Nicotine Tob Res 2010;12(5):483-488

74 Rizwan S, Manning JT, Brabin BJ. Maternal smoking during pregnancy and possible effects of in utero testosterone: evidence from the 2D:4D finger length ratio. Early Hum Dev 2007;83(2):87-90

75 Motlagh MG, Sukhodolsky DG, Landeros-Weisenberger A, et al. Adverse effects of heavy prenatal maternal smoking on attentional control in children with ADHD. J Atten Disord 2011;15(7):593-603

76 Obel C, Olsen J, Henriksen TB, et al. Is maternal smoking during pregnancy a risk factor for hyperkinetic disorder?-findings from a sibling design. Int J Epidemiol 2011;40(2):338-345

77 Max W, Sung HY, Shi Y. Attention deficit hyperactivity disorder among children exposed to secondhand smoke: a logistic regression analysis of secondary data. Int J Nurs Stud 2013;50(6):797-806

78 Ekblad M, Gissler M, Lehtonen L, Korkeila J. Prenatal smoking exposure and the risk of psychiatric morbidity into young adulthood. Arch Gen Psychiatry 2010;67(8):841-849

79 Cornelius MD, Goldschmidt L, Day NL. Prenatal cigarette smoking: long-term effects on young adult behavior problems and smoking behavior. Neurotoxicol Teratol 2012;34(6):554-559

80 Brion MJ, Victora C, Matijasevich A, et al. Maternal smoking and child psychological problems: disentangling causal and noncausal effects. Pediatrics 2010;126(1):e57-e65

81 Cornelius MD, Goldschmidt L, De Genna NM, Larkby C. Longterm effects of prenatal cigarette smoke exposure on behavior dysregulation among 14-year-old offspring of teenage mothers. Matern Child Health J 2012;16(3):694-705

82 Rydell M, Cnattingius S, Granath F, Magnusson C, Galanti MR. Prenatal exposure to tobacco and future nicotine dependence: population-based cohort study. Br J Psychiatry 2012;200(3):202-209

83 Goldschmidt L, Cornelius MD, Day NL. Prenatal cigarette smoke exposure and early initiation of multiple substance use. Nicotine Tob Res 2012;14(6):694-702

84 Anderko L, Braun J, Auinger P. Contribution of tobacco smoke exposure to learning disabilities. J Obstet Gynecol Neonatal Nurs 2010;39(1):111-117

85 Dong T, Hu W, Zhou X, et al. Prenatal exposure to maternal smoking during pregnancy and attention-deficit/hyperactivity disorder in offspring: a meta-analysis. Reprod Toxicol 2018;76:63-70

86 Eiden RD, Zhao J, Casey M, Shisler S, Schuetze P, Colder CR. Pre- and postnatal tobacco and cannabis exposure and child behavior problems: bidirectional associations, joint effects, and sex differences. Drug Alcohol Depend 2018;185:82-92

87 Kristjansson AL, Thorisdottir IE, Steingrimsdottir T, Allegrante JP, Lilly CL, Sigfusdottir ID. Maternal smoking during pregnancy and scholastic achievement in childhood: evidence from the LIFECOURSE cohort study. Eur J Public Health 2017;27(5):850-855

88 Thiering E, Brüske I, Kratzsch J, et al; GINIplus and LISAplus Study Groups. Prenatal and postnatal tobacco smoke exposure and development of insulin resistance in 10 year old children. Int J Hyg Environ Health 2011;214(5):361-368

89 Raum E, Küpper-Nybelen J, Lamerz A, Hebebrand J, Herpertz-Dahlmann B, Brenner H. Tobacco smoke exposure 
before, during, and after pregnancy and risk of overweight at age 6. Obesity (Silver Spring) 2011;19(12):2411-2417

90 Weng SF, Redsell SA, Swift JA, Yang M, Glazebrook CP. Systematic review and meta-analyses of risk factors for childhood overweight identifiable during infancy. Arch Dis Child 2012;97(12):1019-1026

91 Oken E, Levitan EB, Gillman MW. Maternal smoking during pregnancy and child overweight: systematic review and meta-analysis. Int J Obes 2008;32(2):201-210

92 Yang Y, Wang C, Gan Y, et al. Maternal smoking during pregnancy and risk of strabismus in offspring: a meta analysis. Acta Opthalmol 2019;97(4):353-363

93 Kessous R, Wainstock T, Sheiner E. Smoking during pregnancy as a possible risk factor for pediatric neoplasms in the offspring: a population-based cohort study. Addict Behav 2019;90:349-353

94 Singer LT, Min MO, Minnes S, et al. Prenatal and concurrent cocaine, alcohol, marijuana, and tobacco effects on adolescent cognition and attention. Drug Alcohol Depend 2018;191:37-44

95 Chen Y, Liu Q, Li W, Deng X, Yang B, Huang X. Association of prenatal and childhood environment smoking exposure with puberty timing: a systematic review and meta-analysis. Environ Health Prev Med 2018;23(1):33

96 De Genna NM, Richardson GA, Goldschmidt L, Day NL, Cornelius MD. Prenatal exposures to tobacco and cannabis: associations with adult electronic cigarette use. Drug Alcohol Depend 2018;188:209-215

97 Axelsson J, Sabra S, Rylander L, Rignell-Hydbom A, Lindh CH, Giwercman A. Association between paternal smoking at the time of pregnancy and the semen quality in sons. PLoS One 2018;13(11):e0207221

98 Harding R, Maritz G. Maternal and fetal origins of lung disease in adulthood. Semin Fetal Neonatal Med 2012;17(2):67-72

99 Lovasi GS, Diez Roux AV, Hoffman EA, Kawut SM, Jacobs DR, Jr. Barr RG. Association of environmental tobacco smoke exposure in childhood with early emphysema in adulthood among nonsmokers: the MESA-lung study. Am J Epidemiol 2010;171(1):54-62

100 Beyer D, Mitfessel H, Gillissen A. Maternal smoking promotes chronic obstructive lung disease in the offspring as adults. Eur J Med Res 2009;14(Suppl 4):27-31

101 Cole E, Brown TA, Pinkerton KE, et al. Perinatal exposure to environmental tobacco smoke is associated with changes in DNA methylation that precede the adult onset of lung disease in a mouse model. Inhal Toxicol 2017;29(10):435-442

102 Power C, Atherton K, Thomas C. Maternal smoking in pregnancy, adult adiposity and other risk factors for cardiovascular disease. Atherosclerosis 2010;211(2):643-648

103 Liu T, Gatsonis CA, Baylin A, Buka SL. Prenatal exposure to cigarette smoke and benign breast disease. Epidemiology 2010;21(5):736-743

104 Schechter JC, Fuemmeler BF, Hoyo C, Murphy SK, Zhang JJ, Kollins SH(2018). Impact of smoking ban on passive smoke exposure in pregnant non-smokers in the Southeastern United States. Intl J Environ Res Public Health 2018;15:pi:E83

105 CDC. The Health Consequences of Involuntary Exposure to Tobacco Smoke: A Report of the Surgeon General. Atlanta, GA: Centers for Disease Control and Prevention
106 Khader YS, Al-Akour N, Alzubi IM, Lataifeh I. The association between second hand smoke and low birth weight and preterm delivery. Matern Child Health J 2011;15(4):453-459

107 Salmasi G, Grady R, Jones J, McDonald SD; Knowledge Synthesis Group. Environmental tobacco smoke exposure and perinatal outcomes: a systematic review and meta-analyses. Acta Obstet Gynecol Scand 2010;89(4):423-441

108 Peppone LJ, Piazza KM, Mahoney MC, et al. Associations between adult and childhood secondhand smoke exposures and fecundity and fetal loss among women who visited a cancer hospital. Tob Control 2009;18(2):115-120

109 Subramoney S, d'Espaignet ET, Gupta PC. Higher risk of stillbirth among lower and middle income women who do not use tobacco, but live with smokers. Acta Obstet Gynecol Scand 2010;89(4):572-577

110 Nieuwenhuijsen MJ, Dadvand P, Grellier J, Martinez D, Vrijheid M. Environmental risk factors of pregnancy outcomes: a summary of recent meta-analyses of epidemiological studies. Environ Health 2013;12:6

111 George L, Granath F, Johansson AL, Annerén G, Cnattingius S. Environmental tobacco smoke and risk of spontaneous abortion. Epidemiology 2006;17(5):500-505

112 Penzias AS. Recurrent IVF failure: other factors. Fertil Steril 2012;97(5):1033-1038

113 Benedict MD, Missmer SA, Vahratian A, et al. Secondhand tobacco smoke exposure is associated with increased risk of failed implantation and reduced IVF success. Hum Reprod 2011;26(9):2525-2531

114 Tiesler CM, Chen CM, Sausenthaler S, et al; LISA Study Group. Passive smoking and behavioural problems in children: results from the LISAplus prospective birth cohort study. Environ Res 2011;111(8):1173-1179

115 Jones LL, Hassanien A, Cook DG, Britton J, Leonardi-Bee J. Parental smoking and the risk of middle ear disease in children: a systematic review and meta-analysis. Arch Pediatr Adolesc Med 2012;166(1):18-27

116 Chang JS. Parental smoking and childhood leukemia. Methods Mol Biol 2009;472:103-137

117 Lalude 00. Risk of cardiovascular events with hormonal contraception: insights from the Danish cohort study. Curr Cardiol Rep 2013;15(7):374

118 Pomp ER, Rosendaal FR, Doggen CJ. Smoking increases the risk of venous thrombosis and acts synergistically with oral contraceptive use. Am J Hematol 2008;83(2):97-102

119 Shufelt CL, Bairey Merz CN. Contraceptive hormone use and cardiovascular disease. J Am Coll Cardiol 2009;53(3):221-231

120 Saraç F, Öztekin K, Çelebi G. Early menopause association with employment, smoking, divorced marital status and low leptin levels. Gynecol Endocrinol 2011;27(4):273-278

121 Kinney A, Kline J, Levin B. Alcohol, caffeine and smoking in relation to age at menopause. Maturitas 2006;54(1):27-38

122 Matikainen T, Perez GI, Jurisicova A, et al. Aromatic hydrocarbon receptor-driven Bax gene expression is required for premature ovarian failure caused by biohazardous environmental chemicals. Nat Genet 2001;28(4):355-360

123 Windham GC, Mitchell P, Anderson M, Lasley BL. Cigarette smoking and effects on hormone function in premenopausal women. Environ Health Perspect 2005;113(10):1285-1290 